\title{
Enriched School Health for the Effective Healthcare Bio-Activity of Barn Owls
}

\author{
Subhas Chandra Datta* \\ Eco-Club Research Unit, Kanchannagar D.N.Das High School (HS), West Bengal, India \\ *Corresponding author: Subhas Chandra Datta, Eco-Club Research Unit, Kanchannagar D.N.Das High School (HS), West Bengal, \\ India
}

\begin{abstract}
Kanchannagar D.N.Das High School (HS), Kanchannagar, Purba Bardhaman-713102,West Bengal, India, is situated besides the Damodar river and is surrounded by ponds- and agriculture- fields. The school campus, prevails the main old- and tall- tree of banyan tree (Ficus bengalensis) with other trees, nutritional garden with midday meal, exhibited an enriched faunal diversity comprising small mammals, reptiles, toads, small birds and insects. Midday meal in a school depends on quality and supply of healthy foods which are depend on the habitants in the school environment. The rats were spoiling the foods for mid-day meal, rooms, important documents and materials in the school. Once the bats in the banyan tree began to make the school building dirty by their excreta. Different pests significantly reduce food production in the nutritious kitchen garden in school. The pesticides are the most effective means of control, but they are expensive and not environment friendly. To move forward, it will require new and more efficient solutions, technologies, products and it has to fulfill all requirements. Our best endeavor is to focus on the barn owl (Tyto alba Scopoli) which may have important economic implications for school environment as well as agriculture in future. Observations on the dietary habits and behaviors of the barn owl occupying a wooden nest were recorded in September 2018-February 2019 at school. During six months of observations, total consumed animals of barn owl, are analyzed from the regurgitated pellets; rats, mice and moles remained the highest as owls dietary proportions (58.13\%), bats (13.57\%), mongoose $(10.41 \%)$, squirrels (8.89\%), small birds like babblers etc $(6.32 \%)$, insects $(2.22 \%)$ and others animals like toads etc $(0.47 \%)$. Due to mid day meal within the school campus and owl's clear vision during the night, it preferred to consume a variety of rodents inhabiting the kitchen stored as well as school campus. Food grains of mid day meal attracts rodents resulting a rapid increase of rats and mice but the presence of owl compel them to run away from the premises and they become guards for the cleanliness of the school. It can, therefore, serve as a useful "Healthcare Bio-Controller" i.e. Biological Bird of Prey. Their breeding helps to escalate the vegetation system of the school area and made the ponds clean; directly emphasized the ecosystem. Evidently, the barn owl would ensure a substantial management of ecosystem for better growth of economically important crops and their management in agriculture, horticulture as well as pisiculture also. And improves midday meal by supplying quality vegetables also and it would not only be easier way, easily available, cheap but also conserve our biodiversity and improves school environment which will contribute towards "Sustainable Climate, School Health and Development with Joyful learning environment". They are also opening a path of research for the students of our school who are observing them closely. We are amazed to find the coexistence of predator and prey on the same platform where owls and pigeons are found busy in incubation. It does not attacking the pigeons. Owls do not cause any harm to the other resident birds within the campus also and directly or indirectly they are helping us in various ways. They realize the meaning of relationship so they did not feel irritating when visitors, school students went to meet them.
\end{abstract}

Keywords: School health; Barn owls; Healthcare bio-controller; Midday meal; Regurgitated pellets

\section{Introduction}

Number of birds are getting reduced gradually due to the rapid urbanization, poaching, superstation, use of insecticides and the fatal cord of kites [1]. Having been surrounded by green plantation, ponds, rivers and rivulets Kanchannagar D.N.Das High School location wise an ideal place for domestic and migratory birds. The diversity provides good habitat conditions for all animal groups $[1,2]$. Barn owls belong to the top of the food chain and are attracted for the plenty of food availability [3-6]. Midday meal in a school depends on quality and supply of healthy foods which are depend 
on the habitants in the school environment [5]. The rats, moles and mice were spoiling the foods for midday meal, rooms, important documents and materials in the school [1,2]. Once the bats in the banyan tree (Ficus bengalensis L.) began to make the school building dirty by their stools and urinals making our white walls dirty [1-4]. Different pests significantly reduce food production in the nutritious kitchen garden in school ${ }^{5}$. The pesticides are the most effective means of control, but they are expensive and not environment friendly [6-11]. To move forward, it will require new and more efficient solutions, technologies, products and it has to fulfill all requirements. In 2015 it took the initiative to protect and preserve the birds those are the frequenters to the banyan tree within the school campus [3]. For safe nesting various types of boxes (including wooden box for the owl also), pitchers and swings are provided along with water for drinking and bathing, food particles and sand pits. Birds, squirrels, bats, monkeys, owls are the regular frequenters of this tree. They use these means to procreate [3]. In the last three years (2015-2018) number of barred owls increase noticeably [3]. In these three years, a pair of owls lay eggs twice and give birth to 24 owlets, on an average ${ }^{3}$. Eggs are generally laid in the months of May-June and October-November, in the same nest [3].

As the box was damaged by the rainy season (June 2018), the mother barn owl took shelter in the pigeons nest. Recently (from September 2018 to February 2019) in a tilted bench that has been hanged from the ceiling of the veranda, a pair of barn owl (Tyto $a l b a$ ) has nestled along with a pair of rock pigeon (Columba livia) just beside the three classrooms ${ }^{1-2}$. One fine morning we find both of them have laid eggs and engaged themselves in incubation. And there are about 1000 students attending the school and about 50 to 70 students / class are attending the three classrooms where the owl had laid eggs [1,2].

For the present studies, our best endeavor is to focus on the observations on the dietary habits and behaviors of the barn owls (Tyto alba) which may have important, for improves the joyful school environment and economic implications for agriculture by better crop quality and production for midday meal in future. The results would be more realistic in terms of the potentiality of the barn owls, use as potential bio-controller /-agents or environment friendly predator birds, in controlling various pests. Our main aim to investigate new and more efficient solutions, technologies, products and it has to improve joyful school environment and fulfill its food and nutrition requirement which indirectly influence the climate change and resource productive economies enriching quality of midday meal as well as joyful educational environment.

\section{Materials and Methods}

\section{Location and Weather of the Study Area}

The experiment was carried out at the Kanchannagar D.N.Das High School (HS), Kanchannagar, Purba Bardhaman-713102,West Bengal, India, where temperature was $17 \pm 5{ }^{\circ} \mathrm{C}$, relative humidity was $67 \pm 5 \%$, was situated besides the Damodar river and is surrounded by ponds- and agriculture- fields. Bardhaman is extends from $22^{\circ} 56^{\prime}$ to $23^{\circ} 53^{\prime}$ North latitude and from $86^{\circ} 48^{\prime}$ to $88^{\circ} 25^{\prime}$ East longitudes [5,6]. And average rainfall was 150 millimeter [5,6].
The school campus, prevails the main old- and tall- tree of banyan tree (Ficus bengalensis) with other trees, nutritional garden with midday meal, exhibited an enriched faunal diversity comprising small mammals, small birds, reptiles, toads and insects [1,3].

\section{Time of Experiments and Type of Nest}

The experiment was conducted from September 2018-February 2019 in the big wooden nest (dimensions: Length - $180.78 \mathrm{~cm}$; width $-50.5 \mathrm{~cm}$; depth $-15.0 \mathrm{~cm}$ ) which is a tilted bench that has been hanged from the ceiling of the veranda [1,3]. The nest was observed every day thrice at $10 \mathrm{am}, 1 \mathrm{pm}$ and $5 \mathrm{pm}[1-4,12]$. All the data were counted for statistical analysis by the analysis of variance (ANOVA).

\section{Collection of Pellets}

The diet composition of the barn owls were studied by the analysis of the materials found in the pellets and the prey remains collected from the demarked floor-bade underneath the tilted bench nest of owls, nest box and its vicinity, in variable numbers throughout the studies (September 2018-February 2019), surveyed and analyzed $[4,12]$. Solid pellets collection was done on daily basis in the morning (at10 am), afternoon (at 1pm) and in the evening (at $5 \mathrm{pm})$. All the pellets were not included in the samples $[4,12]$. They were carefully numerically numbered and measured with the date and time, placed in polyethylene bags and brought to the laboratory for further analyses [4,12]. All the data were counted for statistical analysis by the analysis of variance (ANOVA).

\section{Analysis the Pellets}

For analysis the pellets were immersed in water in Petri boxes for $10 \mathrm{~min}[4,12]$. Bones and sclerosis fragments recovered from the pellets were separated by morphological categories. Each pellet before being dissected was photographed and length was measured [4,12]. Pellets were cut loose with sharp forceps and contents were checked for small mammals, birds and insects. The dissected barn owl pellets were critically examined and materials identified were designated as small mammals, birds and insects, as predominant prey items. All the identified food items were compared and contrasted with available reference materials for various rodent species, mainly on the basis of their dentition and skull patterns etc $[4,12]$ and the other prey were identified using any recognizable remains $[4,12,13]$. Analysis was done regularly for the six months $[1,4]$. All the data were counted for statistical analysis by the analysis of variance (ANOVA).

\section{Maintenance of Records}

Records were maintained for all the pellets sampling and all the data were counted for statistical analysis by the analysis of variance (ANOVA) to ascertain the monthly variations of barn owl pellets in the study site and their predilection for specific food items, as determined from their pellet analysis $[4,12]$. Species richness estimation regarding the relative population abundance of prey items was calculated $[13,14]$ to explain the results meaningfully.

\section{Observation on Different Behaviors}

Nesting and hunting behavior, egg laying, incubation and hatching behaviors, breeding behavior, sound producing behaviors, 
cleanliness behavior and social behaviors has been observed ${ }^{1-3,12-14}$. Relationship or interaction or attitude among the parents owls, among the hatchlings of owls, pigeons, others birds, students, teachers, closely related staffs, photographers, visitors and media personnel, has also been studied for six months. The position of nest boxes provide direct physical access to observe all [1-3].

\section{Results and Discussions}

\section{Diet spectrum and Frequency of Ingested Barn Owl Preys}

Table 1: Month wise distribution of animals in the owls pallets collected from study area of Kanchannagar D.N.Das High School.

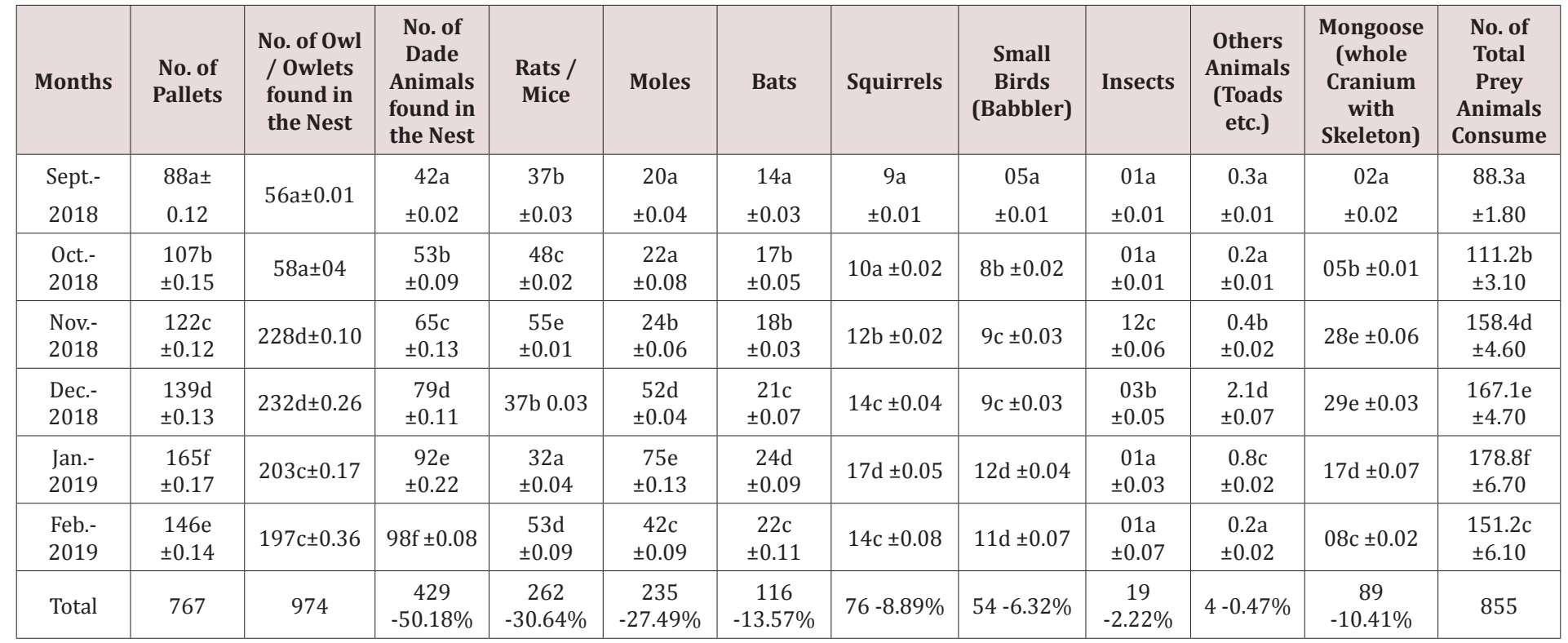

a,b- different small letters in a column show significant difference by 'ANOVA' $(\mathrm{P}<0.01)$.

Table 1 shows that during six months of observations from September 2018 to February 2019, 855 -total consumed prey animals of barn owl, are analyzed from the 767- regurgitated pellets; rats, mice and moles remained the highest as owls dietary proportions (58.13\%), bats (13.57\%), mongoose (10.41\%), squirrels (8.89\%), small birds specially babbler (6.32\%), coleopteran insects $(2.22 \%)$ and others animals like toads $(0.47 \%)$ $(\mathrm{P}<0.1$ by ANOVA).

Regarding the rodent composition in its diet, rats and mice, were found to be most comprehensively depredated food item, while moles and squirrels were the next consumed food item. Of the others, nocturnal mammals bat and mongoose were moderately preferred in the diet but the amphibians toads and coleopteran insects were the least preferred in the school and surrounding environment. These observations suggest that the barn owl is an opportunistic predator taking whatever prey is available ${ }^{3-4}$. It is interesting that barn owls are capable of switching to alternative prey when mammals become rare, but that they return to preferred prey as soon as it becomes available [3,4,12-14].

Highest numbers of pellets and consumed prey animals are found in the month of January due to presence of 6 young owlets and parents $(\mathrm{P}<0.1$ by ANOVA). Highest numbers of dade animals are found in the month of February due to the owlets grow and learn to eat and hunt from their parents $(\mathrm{P}<0.1$ by ANOVA). But highest numbers of owls / owlets are found in the month of December for the quick demand food supply to the 6 growing nestlings owlets $(\mathrm{P}<0.1$ by ANOVA). Highest numbers are consumed by; rat / mice in November, moles and bats and squirrels in January, small babbler birds in February, insects in November, others animals like toads in December and mongoose in November- December $(\mathrm{P}<0.1$ by ANOVA) [3,4,12-14].

Significantly, the size and color of the barn owl pellets were also variable (average length 5 to $8 \mathrm{~cm}$, diameter 12 to $16 \mathrm{~cm}$ and color blackish to deep brown), but sufficiently large to include the scats of variable small mammals, insects and small sized birds [3,4,1214]. Pellet analysis also indicated a relatively high richness of the dietary habit in each sample for the barn owl, therefore, rendering it to be the cosmopolitan bird of prey [4,12-15].

Nevertheless, the percentage composition of small mammals was largest which showed its affinity for them throughout the present studies, lasting from fall through winter, relatively cold and dry weather, which had no impacts from rainfall, as there are incidences of the rain to affect the barn owl populations, and during the rainy days, resource availability certainly increases to affect the barn owl populations [16]. Perhaps, the species richness for barn owl (rodents) would be considerably higher during the November to February, with more availability of food to them, than in the fall and winter seasons [4,12-16]. As majority of the rodents have proved to be destructive to important cash crops causing substantial economic losses, efficiency of barn owls among the woodlands might trigger the reverse trend to control their populations through an efficient control, an augmented global trend for management of pests using non chemical methods to protect the already dwindled agricultural systems, as well manifested in oil-palm plantations in Malaysia using the barn owl populations against rodent pests [17]. 
Of the toads and insects present in the barn owl pellets, can also be regarded as an alternative diet of the owl due to the diminishing of their preferential foods, the rodents, in any habitat [4,12-18], and finally the incidence of avian fauna was found in small proportions in the barn owl pellets, with babbler in relative abundance, whereas, some traces were also found for other birds. Impacts of rodent pests have been unparalleled on sustainable agro-ecosystems in the school, causing considerable depredations to mid day meal stored grains and the materials [5-11,19]. The requirements of the modern day agriculture in wake of alarming increase in population, demand better crop quality and yield [5-11]. Cropping systems throughout India are plagued with various vertebrate pests, mainly the rodents, insects and mammals, disrupting the stability and sustainability of the rich diversity of food crops [5-11]. It, therefore, augments that, propagation of the barn owl in the cultivations would be beneficial to do away with the rodent menace largely, inhibit the damage and economic losses, without putting any serious implications of the sustainability of agro-ecosystems of school and surroundings [13,5-11].

\section{Nesting and Hunting Behaviors}

In 2015 it took the initiative to protect and preserve the birds those are the frequenters to the banyan tree within the school campus [1-3]. For safe nesting various types of boxes, pitchers and swings are provided along with water for drinking and bathing, food particles and sand pits [1-3]. Birds, squirrels, bats, monkeys, owls are the regular frequenters of this tree [1-3]. They use these means to procreate. In the last three years number of barred owls increase noticeably in the wooden owl-box of the banyan tree [13]. In three years, a pair of owls lay eggs twice and give birth to 24 owlets, on an average. Eggs are generally laid in the months of MayJune and October-November, in the same nest [3].

As the owl-box was damaged by the rainy season in the banyan tree, the mother owl recently took shelter in the pigeons nest, which is a tilted bench that has been hanged from the ceiling of the veranda, a pair of barn owl (T. alba L.) has nestled along with a pair of rock pigeon (Columba livia L.) just beside the three classrooms, without hesitation the pigeon family welcomed her and this resulted in a good relationship between them [1-3,20]. The female owl hunted rat, frog, bat, squirrel in order to attract the male one and the effort results in a relationship between them and began to stay together. When hunting they are very swift and will catch their prey unawares with their long and slim feet [1-3,20].

\section{Egg Laying, Incubation and Hatching Behaviors}

One fine morning we find both of them (owls and pigeons) have laid eggs and engaged themselves in incubation. The owl has laid six white colored eggs within 12-days. The average measurements of egg were: length $4.8 \mathrm{~cm}$, width $3.2 \mathrm{~cm}$, weight $20.7 \mathrm{~g}$.We got dumb founded to find this amicable juxtaposition of predator and prey without hesitation the pigeon family welcomed her and this resulted in a good relationship between them [1-4,14-20].

After one month of incubation the six nestling (two male and four females) comes to the earth. It is observed that $1^{\text {st }}$ hatchling is female owl, $2^{\text {nd }}$ one is also female owl, $3^{\text {rd }}$ one is male owl, $4^{\text {th }}$ one is female, $5^{\text {th }}$ one female and last one is again male owl [3-4]. Sex determination has done by morphological characters. Nesting barn owls store prey items at the nest site while they are incubating to feed the young once they hatch. The adult male counterpart has taken responsibility of supplying food. The length of the adult female is $33 \mathrm{~cm}$ and $93 \mathrm{~cm}$ when it spans its wings. And the parent owls always feed and care for the newborns. Within 10-12 days from hatching, the owlets grow and learn to eat and hunt from their parents [1-4,14-20].

\section{Food Supply Behaviors}

The female tears up the food brought by the male and distributes it to the chicks. Initially these make a "chittering" sound but this soon changes into a food-demanding "snore". The bird was conscious about the surrounding environment. On some disturbance, parents flew away from the nest giving an alert call and perched on a palm tree nearer the building. Sometimes two owlets were observed sitting on the nest. The male is the main provider of food until all the chicks are at least four weeks old at which time the female begins to leave the nest and starts to roost in the palm tree. By the sixth week the chicks are as big as the adults but have slimmed down somewhat by the ninth week when they are fully fledged and start leaving the nest briefly themselves. They are still dependent on the parent birds until about thirteen weeks and receive training from the female in finding, and eventually catching prey [1-4,14-20].

\section{Sitting Behaviors}

The young 6-owlets always sit side by side in $180^{\circ}$ angle and two male owlet posses in the middle surrounded by female owlets due to maintaining body temperature as well as defense mechanism. About 70 days after hatching, they leave the nest for their first flight. However, they return to the nest to roost. About 3-5 weeks after they began flying, they then become independent. Eventually, after 90-116 days of full maturity, they are looking for their new nest. In the month of March, all the owls flew away and take safeshelter behind the dry leaves of a palm tree where difficult to see or find out the owls due to same background color of owl and dry leaves [14-21].

\section{Cleanliness Behavior}

Parents owls and 6 nestling owlets always clean the nest and never make dirty by their excreta. We do not get any decomposed materials from the nest excepts some little bones after all the adult owls flew away from the nest. It is noted that owls forms a thin ash colored solid layer in the platform of the wooden nest by cementing substance [1-4,12-21].

\section{Sound Produce During Breeding Behaviors}

During incubation, the male will feed the female and both parents take care of the nestlings. When disturbed at its roosting site, an angry barn owl lowers its head and sways it from side to side, or the head may be lowered and stretched forward and the wings drooped while the bird emits hisses and makes snapping noises with its beak. A defensive attitude involves lying flat on the ground or crouching with wings spread out. They also 'twitter' 
when quarrelling with nest mates. Nest boxes provide direct physical access to the breeding location [1-4,12-22].

\section{Singing Behavior}

It is observed that barn owls do have various types of calls. There are five main categories of calls: screams, snores, hisses, chirrups and twitters, and other calls. The scream category consists of the advertising call (a drawn-out gargling scream), the distress call (a series of drawn-out harsh screams), the warning call (highpitched scream), and the purring call (quiet scream used by male to attract female to a nest site). Snores are self-advertising calls given mostly by females and nestlings. Hisses are long and loud; they are given repeatedly to intimidate predators. Chirrups and twitters are given by males when delivering food and by females when feeding young. Nestlings will often twitter when uncomfortable or quarreling with a nest mate. Other calls include the mobbing call (an explosive yell), copulation call (staccato squeal), and greeting call (used during courtship and food deliveries) [1-4,20-22].

\section{Barn owl Anti-Predator Behaviors}

In the ecological food web the barn owls are predated by large carnivorous mammals, red kites, hawks, eagles, some sakes, humans and their pets, particularly house cats and feral cats. Barn owls are also predated by other owls, for example, the great horned owl [1$4,20-22]$. One day, at the age of 65 days, a female owlet is theft by man for pet in the house but the owl produces large alarming sound when they tide in a big bag. Students hear the owlet voice and inform the headmaster. Then, it is rescue by day-guard and frighten owlet don't come out from the bag when open the mouth of the bag by the headmaster. But, when headmaster enter and hold the owlet by the hand with repeated calling "Barn", the owlet comes out and produces pleasure sound with the movement of head [1-3,20-25].

\section{Barn owl Social Behavior}

Owls always give positive responses for the relationship or interaction or attitude among the parents owls, among the hatchlings of owls, pigeons, students, teachers and closely related staffs specially headmaster and two guards. Owls give negative responses to others birds, photographers, visitors and media personnel. But they behave good positive responses when very close related staffs like headmaster or guards accompany with them. Nest boxes provide direct physical access to observe all. Other sounds produced include a purring chirrup denoting pleasure [1-3,12-25].

\section{Barn owl Communication Behavior}

Barn owls are mainly acoustic, that is, they communicate using sounds [1-3,12-25]. The advertising call is the drawn-out gargling scream which is used often. A series of drawn-out gargling scream indicates that the owl is distressed. Some other vocalizations are a twitter when feeding and during courtship, an explosive yell in response to a mammalian predator and a defensive hissing sound. When they are not breeding they are less vocal [1-3,20-25]. The young one also uses several distinct vocalizations which include a twitter during discomfort, attention seeking and a snoring food call. The barn owl also shows visual communication to its predator. When attacked it squints its eyes, spread its wings, jerks its head back and forth, falls on its back and strikes at the intruder with it feet $[1-3,12-25]$.

\section{Special Responses}

The parents owls flew away from nest when visitors come to the spot without closely acquainted staffs for photography. It took shelter behind the leaves of a palm tree. The headmaster stated that no problem and he shall call the bird back. And started shouting... Barnol..Barnol...come come..Barnol (later he stated that he found the name Barnol to be appropriate for the Barn Owl). Barnol came out and perched on a beautiful perch of a neem tree.

"What a beautiful relationship!" ... when headmaster calls, "Barn, Barn... Look your brothers from Kolkata for photography here". The young owlets also get delighted with thousands of students, teaching and non teaching staffs. All the Barn Brothers are now students forming joyful school environment. It is noted that male owl is more responsive than female owl [1-4,12-25].

\section{Observation on Biodiversity}

Therefore, it is observed that the biodiversity of the campus of Kanchannagar D. N. Das High School [1-3,5-11], it is seen that the procreation of the barn owls are taking place in the same environment where students, staffs, visitors and birds and animals like mynah, dove, magpie, drongo, oriole, bulbul, crow, cuckoo, babbler, kingfisher, woodpecker, migratory birds, squirrel, bats, tailor birds, snake, mongoose, mice, frogs, stray dogs, different types of insects, monkeys etc. are amicably co-existing. Three years ago, the droppings of the bats in the banyan tree use to make our white walls dirty, but surprisingly, it does not occur anymore due to the presence of the owls. Food grains of mid day meal attracts rodents resulting a rapid increase of rats and mice but the presence of owl compel them to run away from the premises [1-4,12-25].

\section{Barn owl Social Responsibility}

We are amazed to find the coexistence of predator and prey on the same platform where owls and pigeons are found busy in incubation. It dose not attacking the pigeons. Owls do not cause any harm to the other resident birds and others within the campus. When the nestlings owlets are able to fly and their food habit resulted them as the "Guard" for the cleanliness of the school [1-3]. Their breeding helps to escalate the vegetation system of the school area and made the ponds clean; directly emphasized the ecosystem. Directly or indirectly they are helping us in various ways. They are influencing the ecosystem as well as joyful school environment and also working as "Bio-controller" and huge support to agriculture, horticulture and pisiculture [1-4]. They are also opening a path of research for the students of our school who are observing them closely.

\section{Conclusion}

These observations suggest that the dietary habits and behaviors of the barn owl, total consumed animals of barn owl, are analyzed from the regurgitated pellets; rats, mice and moles remained the highest as owls dietary proportions (58.13\%), bats (13.57\%), mongoose (10.41\%), squirrels (8.89\%), small birds 
like babblers etc $(6.32 \%)$, insects $(2.22 \%)$ and others animals like toads etc $(0.47 \%)$. Due to mid day meal within the school campus and owl's clear vision during the night, it preferred to consume a variety of rodents inhabiting the kitchen stored as well as school campus. Food grains of mid day meal attracts rodents resulting a rapid increase of rats and mice but the presence of owl compel them to run away from the premises and they become guards for the cleanliness of the school. It can, therefore, serve as a useful "Bio-Controller" i.e. Biological Bird of Prey. Their breeding helps to escalate the vegetation system of the school area and made the ponds clean; directly emphasized the ecosystem. Evidently, the barn owl would ensure a substantial management of ecosystem for better growth of economically important crops and their management in agriculture, horticulture as well as pisiculture also. And improves midday meal by supplying quality vegetables also and it would not only be easier way, easily available, cheap but also conserve our biodiversity and improves school environment which will contribute towards "Sustainable Climate, School Health and Development with Joyful learning environment". They are also opening a path of research for the students of our school who are observing them closely. We are amazed to find the coexistence of predator and prey on the same platform where owls and pigeons are found busy in incubation. It does not attacking the pigeons. Owls do not cause any harm to the other resident birds within the campus also and directly or indirectly they are helping us in various ways. They realize the meaning of relationship so they did not feel irritating when visitors, school students went to meet them.

\section{Acknowledgement}

The work described here has been supported by all staffs, students and guardian as well as whole community. I like to thanks Sri Subrata Mukherjee, Senior District Judge for photography and Sri Basudev Mondal, Assistant English-Teacher of Kanchannagar D.N.Das High School, Kanchannagar, Burdwan, who help for preparation of the manuscripts.

\section{References}

1. Staff reporter (2019a) Increased owls safely in the Kanchannagar D.N.Das High School. 23rd February 2019 in Eisamay State News Paper, Bardhaman.

2. Staff reporter (2019b) Environment friendly owls. 1st March 2019 in Kalam State News Paper.

3. Datta SC (2018a) Increased owl populations in the artificial nest of Kanchannagar D.N.Das High School act as a bio-controller. Khaskatha 13: $50-51$.

4. Hammad AK, Muhammad J, Muhammad S, Muhammad A (2014) Dietary Habits of the Barn Owl (Tyto alba) in an Agricultural Farmland of Faisalabad Pakistan. Int J Curr Microbiol App Sci 3(8): 211-218.

5. Datta SC, Datta B (2018b) Improved midday meal by using cowpea as eco-friendly crop controlling root-knot forming global green, growth and green economy. J Recent Sci.
6. Datta SC, Das R, Chatterjee K, Mondal B, Das R (2016a) Amaranth Plant: Protects Climate, Health and Development by Controlling Root-Knot Disease. J Environ \& Analyical Toxicol 6: 341.

7. Datta SC, Datta R (2016b) Prevention and control of root-knot disease of mulberry plants using bioagents amaranth plants: improving sericulture by protecting climate health, health and development. J Environ \& Sociobiol 13(2): 191-200.

8. Datta SC, Datta R (2017) Acaciasides use as Potential Bio-Agents against Various Plant Pathogens. In Abid Ali Khan MM, Murtaza Abid, Abdeen Mustafa Omer, Binna Rani [Edt.], New Innovations in Environmental Biotechnology.

9. Datta SC, Datta R (2007) Intercropping amaranth with mulberry for managing root-knot nematodes and improving sericulture. Sericol 47(3): 297-302.

10. Datta SC (2006) Effects of Cina on root-knot disease of mulberry. Homeopath 95(2): 98-102.

11. Datta SC (2019) Enriched Sericulture from Effective Treatment of Mulberry Diseases by Homeopath. Med Adv Biochem Biotechnol 7: 084.

12. Torre I, Arrizabalaga A, Flaquer C (2004) Three methods for assessing richness and composition of small mammal communities. J Mammal 85: 524-530.

13. Le LH, Que're' JP (2003) Les Rongeurs de France: Faunistique et Biologie. Institut National de la Recherche Agronomique Editions, Paris.

14. Clark DR, Bunck CM (1991) Trends in North American small mammals found in common barn-owl (Tyto alba) dietary studies. Can J Zool 69: pp. 3993-4002.

15. Taylor I (1994) Barn owls Predator-Prey relationships. Cambridge university press, Cambridge, England.

16. Leirs H, Stenseth NC, Nicols JD, Hines JE, Verhagen P, et al. (1997) Stochastic seasonality and non-linear density dependent factors regulate population size in an African rodent. Nature 389: 176-180.

17. Wood BJ, Chung GF (2003) A critical review of the development of rat control in Malaysian agriculture since 1960s. Crop Prot 22: 445-461.

18. Pavez E (2004) Descripcio'n de las aves rapaces chilenas. In: Mun ozPedreros A, Rau J, Ya'nez J [Edt.] Aves rapaces de Chile. Valdivia: CEA Ediciones.

19. Lathiya SB, Ahmed SM, Pervez A, Rizvi SWA (2008) Food habits of rodents in grain go downs of Karachi. J stored Prod Res 44(1): 41-46.

20. Julius O, Christian B, Friederike R, Yair A, Hermann W, et al. (2015) Visual pop-out in barn owls: Human-like behavior in the avian brain. J Vision 15.

21. Dreiss AN, Ruppli CA, Oberli F, Antoniazza, Sylvain Henry, et al. (2013) Barn owls do not interrupt their siblings. Ani Behav 86(1): 119-126.

22. Moffat CB (1940) The notes of the barn owl. The Irish Naturalists J 7: 289-292.

23. Carl D. Marti (2010) Dietary Trends of Barn Owls in an Agricultural Ecosystem in Northern Utah. The Wilson J Ornithol 122(1): 60-67.

24. Ineich GP, Fontaine B, Gargominy O (2012) Banded geckos, Gekko vittatus (Reptilia, Gekkonidae), as the main prey of barn owls (Tyto alba) on the Torres Islands (northern Vanuatu), New Zealand J Zool.

25. Wolf MH, Katrin G, Hermann W (2007) Vernier acuity in barn owls. Sci Dir Vision Res 47: 1020-1026. 
(C) (i) This work is licensed under Creative

DOI: 10.32474/RRHOAJ.2019.03.000164

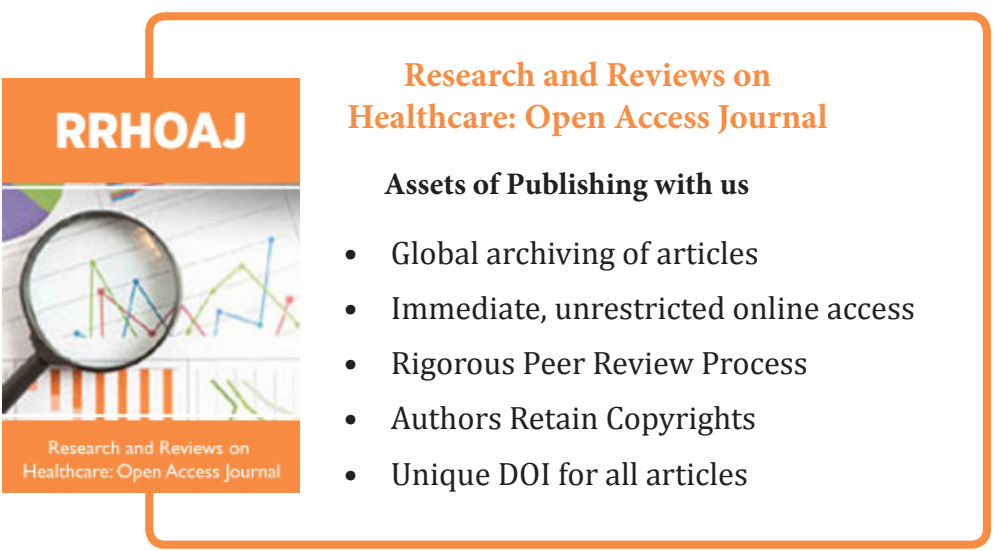

